\title{
FACTORS AFFECTING MATERNAL BEHAVIOUR AND RESPONSIVENESS IN SOWS DURING PERIPARTURIENT AND LACTATION PERIODS
}

\author{
Jacek Nowicki, Czesław Klocek, Tomasz Schwarz \\ Department of Swine and Small Ruminant Breeding, University of Agriculture, 30-059 Kraków, \\ Poland \\ Corresponding author: j.nowicki@ur.krakow.pl
}

\begin{abstract}
Maternal responsiveness of sows affects piglet survival rate by influencing the economic results of breeding. The purpose of this article was to present the relations among housing environment for sows during periparturient period and lactation, endocrine changes in sows, and maternal behaviour and welfare, which ultimately all affect the productive results. The following welfare-related factors were discussed in this paper: the type of farrowing environment, including the type of pen, the area for free movement or confinement crates, alternative loose-housing systems, the importance of nest building for further nursing, and fear as a factor which can impair productivity.
\end{abstract}

Key words: sows, welfare, maternal behaviour, periparturient period, lactation, endocrine changes

\section{Aim of the review}

Pig producers and breeders frequently experience problems with low maternal responsiveness in sows, including crushing, nursing problems and aggressive behaviour directed at the piglets.

It is well known that maternal behaviour associated with the birth and care of offspring is essential for the survival of mammals (Nowak et al., 2000). However, little is known about endocrine-related maternal behaviour of sows. Environmental factors affecting these behavioural patterns and the relation between the endocrine and environmental sources of maternal care have also not been well explored. This is the reason why it was decided to present the scientific achievements in the field of maternal responsiveness of sows.

\section{The development of farrowing housing systems - law regulations}

Soon after birth, neonates participate actively in nipple localisation and suckling and influence the caregiving behaviour of their mother by communicating their 
needs to her (Nowak et al., 2000). These situations may be potentially dangerous for piglets because they can be crushed by their mother. Nowadays, lactating sows are mostly kept in individual pens equipped with metal farrowing crates that restrict their movement (Silerova et al., 2006). Farrowing crates were developed largely to counteract the problem of high piglet mortality, and since the 1960s, there has been a growing trend worldwide to house the farrowing sow in crates of various designs. By housing sows in crates instead of pens, it is possible to decrease the overall space provided to the sow and litter from about $6-10 \mathrm{~m}^{2} / \mathrm{sow}$ to $4 \mathrm{~m}^{2}$ per litter (Barnett et al., 2001). Reduced piglet mortality arises not only from the reduced space for the locomotion of sow, which influences the crushing rate, but also from the reduction of cold or draughty conditions and the provision of supplemental heat in the piglet creep area (English and Morrison, 1984). This is especially important for neonate pigs, as their thermoregulation is inefficient. According to Arey (1993), as further reduction of piglet loss rate (i.e., below $10 \%$ ) becomes more difficult, more emphasis should be placed on developing solutions that enable the expression of the natural behaviour of sows instead of improving construction that restricts the locomotion of sows. These observations have been included in related European regulations. The European Union report on "The Welfare of Intensively Kept Pigs" (1997) states that "The extent to which welfare is reduced by keeping sows in farrowing crates for the whole lactation period needs to be further elucidated". The Council Directive 2001/88/EC states that sows prefer to have social interactions with other pigs when provided with freedom of movement and when faced with environmental complexity. The current practice of keeping sows in continuous close confinement should therefore be prohibited. However, in the UK, for example, approximately $95 \%$ of indoor sows are housed in farrowing crates during farrowing and lactation and this inhibits full interactions between the piglets and sows.

\section{Nest building}

\section{Nest building in feral and domestic sows}

The interactions between a mother and her young are very important for the survival of the neonates as well as the physiological state of the mother, which may influence rearing results. The maternal instinct of the sow before parturition is especially visible in wild sows in free-range or semi-natural conditions because in these circumstances, sows can fully express this instinct.

Before parturition, domestic sows residing in semi-natural conditions separate themselves from the herd and look for a convenient place to build the nest (Jarvis et al., 1997). This behaviour resembles that of wild sows who build their nests out of grass and small branches in an undisturbed place away from other adults. The behaviour related to preparing the nest before parturition represents the development of maternal instinct and care. Six stages have been distinguished in the behaviour performed around the parturition and lactation of sows residing in the free-range system, namely, seeking a place for nest building (1-2 days before parturition), nest building (5-10 hours before farrowing), staying at the nest (10 days after parturition), social integration (10 days to 8 weeks from parturition), and weaning (a gradual process that ends 17 weeks after parturition) (Stangel and Jensen, 1991). In a semi-natural 
environment, sows build their nests far from the places where food is delivered. Four to six hours before parturition, the sow digs a hole in the ground and collects nesting material from an area of about $50 \mathrm{~m}$ around the nesting site. They also become aggressive towards members of their group. They typically cover $1500 \mathrm{~m}$ in 90 minutes during the course of 83 trips, gathering twigs in 47 of these trips and grass tufts in 36 of these trips. After 30 minutes of gathering, sows spread this material as a fine cushion for their nest. After about 2 hours of building activity, sows cease work to rest and do not leave their nest in the hour before farrowing (Stolba and Wood-Gush, 1989). Sows residing in free-range conditions lie in their nests when giving birth to their piglets. Females regularly turn around and sniff their newborn, initiating the first social interaction with their young. However, they never lick their piglets. It is worth noting that immediately before lying down again, the females carefully root the surface of the nesting material as a sign for piglets to avoid crushing (Petersen et al., 1990).

The fact that nest building has been retained despite domestication indicates how robust this maternal behaviour is (Nowak et al., 2000). Many researchers (Haskell and Hutson, 1996; Harris and Gonyou, 1998; Lou and Hurnik, 1998) emphasise that domestic sows housed indoors in farrowing crates also become very active on the day preceding parturition, trying to build their nest. Sows try to build the nest even when they do not have access to straw or other nesting material (Hartsock and Barczewski, 1997; Nowicki and Klocek, 2004). The importance of a nest is evident when the developmental stage of the neonates is considered. The young are small, lack fur and have reduced thermoregulatory abilities, as they depend on an external source of heat (Nowak et al., 2000). Moreover, in the case of wild boars, it also serves as a form of protection from predators.

\section{Factors initializing the nest building behaviour}

There are several explanations for factors that trigger and initiate the maternal behaviour as represented and expressed by nest-building activity. It starts with an increase in prolactin (PRL) concentration and ends with an increase in oxytocin (Castren et al., 1993). This finding was confirmed by Widowski et al. (1990), who reported that increasing prolactin or changes in steroid concentration is important for triggering nest-building activity. Other results (Lawrence et al., 1994) show that there is no clear relation between the pre-farrowing rise of PRL and nest-building behaviour. In the above-mentioned studies, there was no prolactin increase in some of the observed sows, but they still built their nests. Rushen et al. (2001) also suggested a limited role of prolactin in nest-building stimulation because on the 113th day of gestation, the mean concentration of prolactin was correlated with the frequency of postural changes but not with other behavioural measures. Some authors (Boulton et al., 1997) report that this behaviour is performed by gilts and is triggered by prostaglandin $\mathrm{F}_{2 \alpha^{\circ}}$. The investigation for the preference of gilts to pens with and without bedding seems to confirm this theory. Gilts were treated with saline and $\mathrm{PGF}_{2 a}$. Both groups of gilts preferred pens with bedding; however, pigs with administered $\mathrm{PGF}_{2 \alpha}$ spent more time on rooting and carrying straw than gilts treated with saline. The above-mentioned behaviour was interpreted as a form of nest building (Burne et 
al., 2001). It was stated that $\mathrm{PGF}_{2 \alpha}$ affected the behaviour related to straw. Besides internal factors triggering the nest-building activity, external or environmental factors might modify these behavioural patterns (Jarvis et al., 1997). It seems that the concentration of hormones important for preparing the nest, proper parturition as well as further lactation may be modified by environmental factors. Access to straw and the possibility of free movement seems to be the most pivotal. In a study that investigated the effect of straw deprivation on the changes in $\mathrm{PGF}_{2 \alpha}$-induced nesting behaviour, half of the gilts were deprived of straw. Investigated gilts were treated by saline or $\mathrm{PGF}_{2 \alpha}$. Pigs with administered $\mathrm{PGF}_{2 \alpha}$ displayed a significantly higher frequency of rooting and pawing and stayed longer than gilts treated with saline. It is worthwhile to observe that deprivation of straw significantly shortened the time spent on rooting in $\mathrm{PGF}_{2 \alpha}$-treated gilts (Burne et al., 2000). This may suggest that $\mathrm{PGF}_{2 \alpha}$-induced nest building is affected by environmental feedback. Moreover, positive correlations between interest in litter and replacing activities and prolactin levels from the day preceding parturition have been observed (Nowicki and Klocek, 2004). It is interesting to note that the highest prolactin level and interest in straw was found on the day of farrowing in sows housed in pens covered with plenty of straw, thus enabling free movement. The lowest prolactin level on the day of parturition was found in sows housed in farrowing crates with a slatted floor, and the level was intermediate in sows housed in straw-bedded crates (Nowicki and Klocek, 2004). This may suggest that there is a relation between access to straw, possibility of free movement and prolactin concentration. According to Jensen (1993), the nest-building activity of sows consists of two phases. The first one is regulated internally and includes preparing the place for building through rooting and pawing. The second one is comprised of cushioning the material into the nest and depends on external stimuli such as temperature and access to the proper nesting material. The investigation of the influence of different external factors (i.e., sand, concrete floor or access to straw) on nest-building and periparturient activity showed that the availability of straw increased the duration of nest building and rooting. Access to straw increased the total pre-parturient activity, especially activity associated with nest building. The availability of straw also led to reduced time gaps between the expulsion of the first and third piglets. Moreover, significant positive correlations were found between the time of nest building and maternal responsiveness after farrowing. It has been suggested that the presence of environmental stimuli had an effect on the time of nest building, shortening the first part of parturition as well as reducing the risk of crushing piglets (Thodberg et al., 1999). Wischner et al. (2009) showed three actions which should be put into practice:

- suitable material and space for nest building should be provided in the preparturient period,

- alternative pens and nest building material should be tested,

- results from the researches should be implemented into consistent EU regulations.

\section{Welfare implications of maternal behaviour}

Not only is the presence of proper nesting material important for sows, but the space for movement is also responsible for the welfare of sows during the peripar- 
turient period. Thodberg et al. (2002) carried out an experiment in which gilts were housed in groups during gestation; second parity sows were restrained in individual stalls. One week before expected farrowing, the sows were moved to one of two farrowing environments, namely, farrowing crate where sows were restrained by bars or an individual gap divided into a roofed nesting and feeding area with sand and straw. Both gilts and sows started to root earlier, and the duration of pre-partum rooting was significantly longer in the gaps compared to the crated sows. The duration of farrowing and the mean birth interval between piglets were longer in crates. Longer farrowing in crated sows was due to reduced nest building in the crated gilts, resulting in poor feedback and thereby prolonging farrowing. This is supported by the negative correlations between nest building and duration in farrowing. Lawrence et al. (1997) found that the limitation of space for movement significantly modifies the preparturient behaviour of sows. In their experiment, gilts housed in pens with straw $(2 \times 3 \mathrm{~m})$ from $6-12$ hours before parturition spent an average of $27 \%$ of their time being interested in the litter and only $3 \%$ on activities directed to the floor or other pen parts. In contrast, sows housed in crates without straw for the same time period spent $12 \%$ of their time being interested in floor and other pen equipment (i.e., barns or crates). These behaviours directed at the various parts of the pen can be recognised as attempts at nest building in the confinement. It is suggested that housing sows with limited possibility of movement may cause a stress reaction in them. Furthermore, the failure to build a nest can cause apathy and frustration in sows. Many signs of conflict and frustration have been observed in confined sows (Meunier-Salaün and Dantzer, 1990). These include increased aggression, displacement activities, immobility, flight or inhibition responses as well as nervousness and, as will be defined below, stereotypic behaviour (Meunier-Salaün and Dantzer, 1990). Some authors suggest that there may be a relationship between these signs of aggression and an increase in the hormones responsible for the stress reaction (Lawrence et al., 1997). However, the physiological consequences of such situations must be further investigated.

\section{Abnormal behaviour and aggression}

Stereotypic behaviour was identified as regularly repeated, identical movements greater than 1 minute in duration with no apparent function (Borell and Hurnik, 1990). The role of stereotypes is not completely known except that they are mainly displayed by animals residing in monotonous environments (Lawrence and Terlouw, 1993). They also occur during frustration and conflict (Meunier-Salaün and Dantzer, 1990) and are recognised as an indicator of coping problems (Barnett et al., 2001) and poor welfare (Broom, 1996). Stereotypes of tethered or restrained sows typically involve oral activities, such as bar or chain biting. Before parturition, these are displayed at a higher rate as the tendency to engage in nest building grows, and it decreases dramatically during lactation (Meunier-Salaün and Dantzer, 1990) due to the positive effect of the presence of piglets, proper level of hormones during lactation or the simultaneous influence of both of these factors (Dantzer, 1986). Stereotypes are rarely or not observed at all in periparturient period in pens covered with plenty of straw (Nowicki et al., 2003). 
Frustration and stress in confinement is not only displayed by the above-mentioned abnormal behaviour. An important indicator in the welfare assessment is cortisol concentration (Broom, 1996). Before parturition, cortisol concentration increases and is visible from the second day before parturition. However, cortisol reaches its highest level on the day of farrowing. After parturition, cortisol concentration decreases (Baldwin and Stabelfeldt, 1975). Jarvis et al. (1997, 2001) found that the housing system may modify (or increase) the stress reaction. Before gilts were moved into farrowing building, the cortisol level in all animals was similar. The differences appeared after the gilts were moved into farrowing crates without straw and farrowing pens with straw bedding, which enabled the free movement of each sow. During 6-12 hours before parturition in both groups of gilts, there was an increase in cortisol level, although it was statistically significant and higher in gilts housed in crates. In the latter group, cortisol level decreased about 6-12 hours before parturition, but it was still significantly higher than in the gilts housed in pens with straw bedding.

Some abnormal behaviour may be more dangerous for piglets. Aggresion towards piglets occurs sometimes in domestic sows. Savaging leads to the attack on one or more piglets which result in death by biting. Chen et al. (2008) found that the incidence of savaging tended to be higher in gilts than in sows and savage sows had a greater frequency of posture changes from before parturition through the expulsive phase. They concluded that savaging is part of a more generalized behavioural pathology that includes increased excitability and is not specifically piglet directed.

\section{Crushing of piglets}

Lactation is the period during which the sow has the most influence over her offspring's behaviour (Beattie et al., 1996). Data mentioned above suggests that widely used farrowing crates (especially those with slatted floors) decrease the possibility of the sow expressing a natural, maternal instinct and probably do not protect the piglets properly because they inhibit natural maternal responsiveness in frustrated sows. Almost $80 \%$ of the total piglet deaths occur on the day of parturition and within 3-4 days after birth (Svendsen, 1992). The majority of risky situations occur during the first 24-36 hours after birth (Marchant et al., 2001), and the deaths caused by crushing depend not only on the design of the farrowing environment but also on the maternal responsiveness of each individual sow. A very interesting indicator of maternal protectiveness has been presented by Andersen et al. (2005). This indicator was described as nosing during posture changes, which distinguished the so-called "non-crushers" from the "crushers". These authors also used nest-building activity, nose contact initiated by the sow, and sow response to the distress calls of piglets to assess their protectiveness. The confinement of the sow during farrowing is a factor inhibiting socialisation by restricting nose-to-nose contact between the sow and its offspring (Petersen et al., 1990). Wechsler and Hegglin (1997) reported that the maternal responsiveness to the sounds (or screams) of piglets trapped under the sow is an individual trait. In more susceptible sows, a lower number of crushed piglets were discovered. Nevertheless, the housing system seems to influence or modify the maternal response. In crated sows, crushing mostly occurs when the sow lies down, 
and it almost never occurs when the sow rolls over according to Weary et al. (1996). According to Damm et al. (2005), there is quite good understanding of lying down behaviour of sows and its association with the risk of piglet crushing. Quick lying down has previously been interpreted as an indication of the sow's comfort but is detrimental for piglets because it may lead to more crushing due to the piglets' inability to dodge a quickly descending sow (Harris and Gonyou, 1998). Almost 90\% of piglet crushings were caused by swift lying down from a standing position and rolling from lying on the udder to lying on the side (Weary et al., 1998). Being careful when moving from standing to lying did not change significantly during lactation (Valros et al., 2003), although the frequency of standing to lying increases over time in lactation. It is suggestive of the individual characteristics of sows. The frequency of standing to lying correlates positively with the percentage of sows lying on the udder, and a high frequency of posture changes may indicate that the sow is trying to avoid piglet stimulation or that she feels uncomfortable (Valros et al., 2003). Previous research by Nowicki and Klocek (2006) found that the shortest lying down time was found in sows housed in farrowing pens as compared to crates. However, the differences were not statistically significant. Harris and Gonyou (1998) also found that the time taken to lie down varied with the type of farrowing accommodation and was shortest in penned sows. That would indicate that the risk of piglets being crushed is higher in pens, but the results by Nowicki and Klocek (2006) concerning their rolling behaviour does not fully confirm this. An important question arises about whether the construction and design of a farrowing environment limits the possibility of expressing maternal instinct, thereby decreasing the risk of piglets being crushed (farrowing crate), or whether it fully enables the expression of maternal behaviour that would naturally minimise the loss of piglets. Breeders in practice are inclined towards the first proposition because most of the sows in European countries farrow in crates (Hendriks et al., 1998). Contrary to lying down, very little is known about rolling behaviour and factors that affect it as well as its association with piglet crushing (Damm et al., 2005). In a study by Nowicki and Klocek (2006), the number of instances of rolling behaviour was slightly higher in crated sows than in penned sows. Weary et al. (1998) also found that the number of instances of rolling behaviour differed according to the farrowing accommodation. Sows housed on concrete floors rolled less from lying on their side to lying on the udder than sows on plasticised floor. The results of the experiment conducted by Andersen et al. (2005) indicate that sows referred to as the "non-crushers" (i.e., sows that did not crush piglets) showed a tendency for fewer rollover movements during resting in the first two hours of parturition than the "crushers". However, it is unrealistic to completely prevent rolling because it is connected to the suckling attempts initiated by the piglets (Damm et al., 2005). Wischner et al. (2010) showed that sows which did not crush the piglets, especially primiparous ones - performed sniffing as an element of pre-lying behaviour significantly more often and with longer duration than sows which crushed piglets. "Nosing", often in combination with "looking around", was significantly more frequent in primiparous sows which did not crush piglets than in primiparous sows which crushed their offspring. Moreover, sows which did not crush piglets looked around more often before descending from standing to lying by 
kneeling on front legs. Therefore these authors found sniffing, looking around and nosing as components of the pre-lying behaviour representing useful elements to characterise the maternal responsiveness of sows.

The provision of nest materials may be an efficient way of reducing the risk associated with rolling because nest material can modify the behaviour pattern and perhaps reduce the risk of crushing by providing a cushioning effect (Herskin et al., 1998). Bugnacka et al. (2007) demonstrated that sows housed in crates were more aggressive to their newborn piglets and also more nervous during parturition than sows housed in Danish pens.

Burri et al. (2009) investigated the influence of straw length and room temperature on dangerous situations for piglets. Sows in pens with short-cut straw manipulated the pen equipment more frequently during the $10 \mathrm{~h}$ before farrowing than sows in pens with long-stemmed straw. The number of dangerous situations was associated positively with the time the sow spent nest-building during farrowing, and with the occurrence of events in which she laid down laterally without leaning against a wall and with more than two piglets present during the first 3 days after farrowing, The incidence of dangerous situations also decreased over the first days after farrowing, increased with the time the sow spent moving around before lying down, and was inversely related to the duration of the lying-down movement. Moreover, the more piglets there were present during a lying-down movement the higher was the incidence, especially if they were not grouped on only one side of the sow's body. Room temperature was associated positively with the time it took the piglets to get to the creep area after birth and negatively with the time they spent there but did not affect the incidence of dangerous situations. Straw length had no significant influence on the total pre-weaning piglet mortality or the proportion of piglets crushed.

Melisova et al. (2011) determined which component of the pre-lying behaviour influenced piglet location (piglets in an area identified as the danger zone and in the sow area) and piglet clustering at the moment of lying down. In contrast to what they predicted, sniffing increased the proportion of piglets (out of the litter size) in the danger zone, sow area and piglet clustering. Sow vocalization attracted the piglets to the sow and thus increased the proportion of piglets in the danger zone. They found no effect of pre-lying communication, piglet location or piglet clustering on the incidence of crushing. The frequency of pre-lying communication, such as sow vocalization decreased and nudging tended to decrease within the following days, whereas the frequency of sniffing remained stable. Piglets with higher birth weight were more likely to be present in the danger zone.

Cui et al. (2011) showed the differences between the breeds in the postural changes and maternal responsiveness. They investigated the Landrace pigs as well as the Minpigs. It was shown that Minpig sows and Landrace sows were different in piglet-crushing behaviour (rolling, lying down from a sitting position or a standing position), lateral recumbency, ventral recumbency, and sitting and nursing behaviour (frequency of nutritive nursing and proportion of nursing terminated by the sow). The Minpig sows lie down at higher frequencies from a standing position, but crushing resulting from this movement in the Minpig sows was much less common than in the Landrace sows. Their results show that Minpig sows show stronger maternal 
instincts through their behavioural postures and their carefulness with piglets compared with the Landrace breed.

The results obtained by Ringgenberg et al. (2012) show that the gestation environment may also have an impact on the maternal responsiveness of sows. The authors quoted above noticed that social stress during gestation had worsened the maternal response of sows especially in case of the latency of reaction for piglet vocalization which was longer than in control group.

\section{Alternative housing systems and nursing}

Nowadays, welfare trends have increased interest in alternative housing systems for sows and piglets during the lactation period. Group housing, especially on dense beds of straw, has become quite popular. A comparison of nursing behaviour between individual (i.e., straw bedded pens instead of farrowing crates) and group housing on commercial farms showed that there was no significant difference in the total number of nursings between the two groups. However, on group housing farms, sows terminated a higher proportion of nursings and allowed for the postejection massage of piglets for a shorter time. In contrast, nursing synchronisation was higher among sows on group housing farms than on individual housing farms (Šilerová et al., 2006). In some countries, the outdoor system is used for rearing piglets with their mothers. The results from Hötzel et al. (2004) show that piglets raised in an intensive outdoor system were more active in general and had more extensive behavioural repertoire due to more movement and exploration of the environment than confined piglets. The confined piglets spent more time interacting with the sow and nursing than outdoor piglets. The lower frequency of nursing and lower social contact with the dam led to more frequent solid food consumption at an earlier age. The ability of the sow to control nursing frequency in the outdoor system appeared to be beneficial for both the litter and the sow. While in confinement, the sows were in constant contact with their litter in the outdoor system and were able to regulate nursing frequency. Interestingly, despite the higher levels of nursing in the confined system, growth rates were not affected (Petersen et al., 1995). This may suggest that in the absence of other materials, confined piglets might have used the udder as an object of manipulation activities, and this may explain nursings that do not result in the let-down of milk.

\section{The role of human-animal relations}

Besides the housing system, there are other factors that influence maternal behaviour. Some factors such as human-animal relations have not been recognised to be of much importance. The effect of these relations can be investigated through the positive handling test (i.e., pleasant touching, talking friendly and quietly, and feeding) as proposed by Andersen et al. (2006). The test was used in the later stages of pregnancy, and its influence on the maternal behaviour of sows was investigated. The findings show that there is a shorter farrowing duration in sows with low fear towards humans compared to those with high fear. Furthermore, fearful sows spent less time farrowing when they were positively handled. The above-mentioned study showed that in low confidence sows, short-term positive handling in the later stages 
of pregnancy greatly reduced their fear towards humans. However, it had no significant effects on piglet survival or weight gain in the first week after farrowing. It is obvious that positive handling cannot be used permanently in large farms; however, these findings seem to be rather interesting because the sows with low fear towards humans are easier to work with.

Lensink et al. (2009) found that the sows' responses to the presence of humans around farrowing could partly contribute to piglet crushing through increased reactivity and getting up and lying down behaviour. They found that higher transfer speed to the farrowing room was correlated with a shorter latency to change position and with more postural changes and was correlated with higher crushing levels.

\section{Problems with nursing}

Apart from crushing, breeders also have problems with the nursing behaviour of sows. It is well known that between birth and weaning, nursing behaviour of sows changes with a gradual decrease in maternal investment (Farmer and Robert, 2006). Nursing behaviour is closely related to milk ejection, and piglets have access to milk only during that short period. A low frequency of nursings (Špinka et al., 1997) and a high proportion of nursings without milk ejection (Illmann et al., 1999) are the most important factors that reduce the production and intake of milk. The willingness of sows to nurse depends on how hungry the sow is (Thodberg and Jensen, 2005). If the motivation to eat is strong, the motivation to nurse the piglets is lost in the competition between the two motivations. This research shows that the latent predisposition to assume a nursing posture is affected by piglet behaviour; the more active the piglets are, the sooner the sow assumes a nursing posture. Some research results show that sow-directed piglet behaviour increases with time since their last nursing (Jensen et al., 1998; Pajor et al., 2000). However, Thodberg and Jensen (2005) indicated that the hunger of sows seems to influence the behaviour of piglets, as does her willingness to nurse them. Instead of inviting the piglets, hungry sows give them a signal to stay away. Hence, breeders should feed sows well, as it may increase their willingness to nurse. The nursings of individual sows tend to be highly synchronised in time, probably through acoustic communication (Maletinska and Špinka, 2001). Moreover, in the group housing system, nursing synchronisation helps to reduce cross-suckling (Maletinska and Špinka, 2001). On farms that use group housing system for lactating sows, the ventilation system purposefully generates noise so that the grunting of a successful nursing sow, a characteristic feature of milk ejection, cannot be heard by other sows.

The role of well-known non-nutritive nursings is unclear; however, the results of Illmann et al. (1998) indicate that these nursings probably have a negative effect on milk production. The additional massage provided by them does not induce higher milk output per milk ejection. Oxytocin concentrations peak during successful nursings; however, the magnitude of the peak is more pronounced in some sows than in others (Valros et al., 2003). After milk ejection, oxytocin concentrations decline gradually to a baseline concentration. However, not all nursings coincide with clear peaks in oxytocin; nursings that do not include milk ejection do not coincide with clear peaks in oxytocin. Prolactin is known to be stimulated by udder massage; 
however, researchers have failed to find an association between prolactin concentration and milk output (Valros et al., 2004), although prolactin has been found to be essential for the onset and maintenance of lactation in sows (Farmer et al., 1998). This may lead to our next research question: before farrowing, can higher prolactin concentration caused by the environmental factors (e.g., straw bedding or free movement) make lactation more efficient? During lactation, prolactin release in sows has also been influenced by massaging time and litter size (de Pasillé et al., 1993).

\section{Tests for maternal responsiveness}

There is a great range of factors affecting the maternal behaviour of sows. Maternal ability varies from individual to individual. Therefore, the fact that almost no direct breeding for good maternal abilities has been conducted is very striking, as most breeders suffer from crushings and problems with nursing. Breeding is rather directed at increasing leanness, which may negatively affect reproductive performance (Bečkova et al., 2005). The improvement in maternal care is achieved mainly through the use of maternal breeds in the proper place in the crossing scheme, but coupled with increasing leanness, the maternal potential of sows decreases. Surprisingly, tests for maternal responsiveness as proposed by Pitts et al. (2002) do exist. The steps are as follows. First, a strange or foreign piglet is introduced to the pen, and the sow's behaviour is observed for 5 minutes (i.e., aggression is observed). Then, a recording of vocalisations from simulated piglet crushing is played near the sow as she starts to lie down. The time it takes to get up as well as the motivation to get up is considered. The next proposed test involves an empty pen; while the sow is away from her home pen, her litter is removed, and the behaviour of the sow is recorded. Another test involves an isolated piglet; in an empty pen, a recording of a piglet isolated immediately before a nursing bout is played, and the behaviour of the sow is observed. The last proposed test is known as litter return; the litter is replaced in the sow's pen, and her behaviour is recorded. A similar test determining the maternal responsiveness of sows was proposed by Nowicki and Schwarz (2010) where the voices of piglets in danger were the basis of the maternal responsiveness tests. These tests compared the reaction of sows in two different farrowing environments. It was found that the sows are much more susceptible when they are housed in free movement pens vs. farrowing crates.

\section{Conclusion}

The behavioural and physiological features of the sow lead to maternal success. Behaviour and endocrinology must be considered together and emphasised more. All of these factors interact and have considerable influence on offspring survival, offspring growth and rearing results. Maternal responsiveness tested using behavioural tests may be also taken into account in breeding programmes, which may improve the results of rearing piglets. The proposals made by Pitts et al. (2002) and Nowicki and Schwarz (2010) could be a basis for the further development of methods for testing the behavioural maternal responsiveness of sows. Moreover, the three actions proposed by Wischner et al. (2009) should be put into practice. It seems necessary 
to introduce the scientific achievements in the field of requirements for sow housing systems into the European legislation.

It is hoped that the behaviour of animals and particularly the sow maternal behaviour ceases to be only a niche topic, because the production results obtained depend on many factors, which were shown in this paper.

\section{References}

A nd e r s e n I.L., B erg S., B o e K.E. (2005). Crushing of piglets by the mother sow (Sus scrofa) - purely accidental or a poor mother? Appl. Anim. Behav. Sci., 93: 229-243.

A nderse n I.L., B erg S., B o e K.E., Edwards S. (2006). Positive handling in late pregnancy and the consequences for maternal behaviour and production in sows. Appl. Anim. Behav. Sci., 99: 64-76.

A r e y D.S. (1993). The welfare of pigs in confined and non-confined farrowing systems. Pig News Inf., $14(2): 81 \mathrm{~N}-84 \mathrm{~N}$.

B a ldw in D.M., S t a b e $\mathrm{n}$ fe $1 \mathrm{~d} t$ G.H. (1975). Endocrine changes in the pig during late pregnancy, parturition and lactation. Biol. Reprod., 12: 508-515.

B arnett J.L., Hems worth P.H., Cronin G.M., Jongman E.C., Huts on G.D. (2001). A review of the welfare issues for sows and piglets in relation to housing. Aust. J. Agr. Res., 52: $1-28$.

B e a t $t$ i e V.E., W a $1 \mathrm{k}$ e r N., S n e d d o n I.A. (1996). Influence of maternal experience on pig behaviour. Appl. Anim. Behav. Sci., 46: 159-166.

B e č k ov a R., D a n e k P., V a c la v k ov a E., R o z k ot M. (2005). Influence of growth rate, backfat thickness and meatiness on reproduction efficiency in Landrace gilts. Czech J. Anim. Sci., 50: $535-544$.

B or e 11 E. v o n, H u r n i k J.F. (1990). Stereotypic behaviour and productivity of sows. Can. J. Anim. Sci., 70: 953-956.

B oulton M.I., Wi ckens A., B rown D., G oode J.A., Gilbert C.L. (1997). Prostaglandin F2alpha-induced nest-building in pseudopregnant pigs. I. Effects of environment on behaviour and cortisol secretion. Physiol. Behav., 62: 1071-1078.

B ro om D.M. (1996). A review of animal welfare measurement in pigs. Pig News Inf., 17: $109 \mathrm{~N}-114 \mathrm{~N}$.

B u g n a c k a D., G r u d n i e w s k a B., J a r c z y k A. (2007). Observations of perinatal period on primiparous sows kept in different types of farrowing pens (in Polish). Rocz. Nauk. PTZ, 3/3: 123-133.

B urne T.H.J., M urfitt P.J.E., Gil bert G.L. (2000). Deprivation of straw bedding alters PGF2induced nesting behaviour in female pigs. Appl. Anim. Behav. Sci., 69: 215-225.

B urne T.H.J., M urfitt P.J.E., Gil bert G.L. (2001). Influence of environmental temperature on PGF2-induced nest-building in female pigs. Appl. Anim. Behav. Sci., 71: 293-304.

B u r r i M., W e c h s l e r B., G y g a x L., W e b e r R. (2009). Influence of straw length, sow behaviour and room temperature on the incidence of dangerous situations for piglets in a loose farrowing system. Appl. Anim. Behav. Sci., 117: 181-189.

Castren H., Algers B., Pasille A.M.B., Rushen J., Uvnas-Moberg K. (1993) Pre-parturient variation in progesterone, prolactin, oxytocin and somatostatin in relation to nest-building in sows. Appl. Anim. Behav. Sci., 38: 91-102.

Chen C., Gilbert C.L., Yang G., Guo Y., S egonds-Pichon A., Ma J., Evans G., Brenig B., S arge nt C., A ff ar a N., Hu ang L. (2008). Maternal infanticide in sows: Incidence and behavioural comparisons between savaging and non-savaging sows at parturition. Appl. Anim. Behav. Sci., 109: 238-248.

Council Directive 2001/88/EC of 23 October 2001 amending Directive 91/630/EEC laying down minimum standards for the protection of pigs. Official Journal of the European Communities, 1.12.2001. 
Cui S., Chen D., Li J., Li X., Y in G., B a o J. (2011). A comparison of postural changes and maternal responsiveness during early lactation in Landrace and Minpig sows. Appl. Anim. Behav. Sci., 131: 40-47.

D a $\mathrm{m}$ m B.I., F o r k m a n B., P e derse n L.J. (2005). Lying down and rolling behaviour in sows in relation to piglet crushing. Appl. Anim. Behav. Sci., 80: 3-20.

D a n t z e r R. (1986). Behavioral, physiological and functional aspects of stereotyped behaviour: a review and re-interpretation. J. Anim. Sci., 62: 1776-1786.

De Pasille A.M.D., Rushen J., Foxcroft G.R. Aherne F.X., Shaefer A. (1993). Performance of young pigs: relationships with periparturient progesterone, prolactin, and insulin of sows. J. Anim. Sci., 71: 179-184.

English P.R., M or ris o n V. (1984). Causes and prevention of piglet mortality. Pig News Inf., 5: 369-376.

European Commission (1997). The Welfare of Intensively Kept Pigs. Report of the Scientific Veterinary Committee, Doc XXIV/B3/ScVC/0005/1997 final. Adopted 30 September 1997.

F a r m e r C., R o bert S. (2006). Behavioural responses of sows and piglets from two genotypes to recorded nursing grunts played throughout lactation. Appl. Anim. Behav. Sci., 96: 33-42.

F a r m e r C., R o b e r t S., R u s h e n J. (1998). Bromocryptine given orally to periparturient or lactating sows inhibits milk production. J. Anim. Sci., 76: 750-757.

$\mathrm{H}$ a r r i s M., G o n y o u H.W. (1998). Increasing available space in a farrowing crate does not facilitate postural changes or maternal responses in gilts. Appl. Anim. Behav. Sci., 59: 285-296.

Harts o ck T.G., B a rczewski R.A. (1997). Prepartum behavior in swine: effects of pen size. J. Anim. Sci., 75: 2899-2904.

H a s k e 11 M.J., H u t s on G.D. (1996). The pre-farrowing behaviour of sows with access to straw and space for locomotion. Appl. Anim. Behav. Sci., 49: 375-387.

Hendricks H.J.M., Ped ersen B.K., Vermeer H.M., W it tmann M. (1998). Pig housing systems in Europe: current distributions and trends. Pig News Inf., 19: 97N-104N.

H e r s k in M.S., J e n s e n K.H., T h o d b e r g K. (1998). Influence of environmental stimuli on maternal behaviour related to bonding, reactivity and crushing of piglets in domestic sows. Appl. Anim. Behav. Sci., 58: 241-254.

Hötzel M.J., Pinheiro Machado F. L.C., Wolf F.M., Dalla Costa O.A. (2004). Behaviour of sows and piglets reared in intensive outdoor or indoor systems. Appl. Anim. Behav. Sci., 86: $27-39$.

I $11 \mathrm{~m}$ a n n G., S p i n k a M., S t e t k o v a Z. (1998). Influence of massage during simulated non-nutritive nursings on piglets' milk intake and weight gain. Appl. Anim. Behav. Sci., 55: 279-289.

I $11 \mathrm{~m}$ a n n G., S p i n k a M., S t e t k o v a Z. (1999). Predictability of nursing without milk ejection in domestic pigs. Appl. Anim. Behav. Sci., 61: 303-311.

Jarvis S., Lawrence A.B., McLean A.K., Deans L.A., Chirnside J., Calvert S.K. (1997). The effect of environment on behavioural activity, ACTH, $\beta$-endorphin and cortisol in prefarrowing gilts. Anim. Sci., 65: 463-472.

Jarvis S., Van der Vegt B.J., Lawrence A.B., McLean K.A., Deans L.A., Chirns i d e J., C a lvert S.K. (2001). The effect of parity and environmental restriction on behavioural and physiological responses of pre-parturient pigs. Appl. Anim. Behav. Sci., 71: 203-216.

J e n s e n P. (1993). Nest building in domestic sows: the role of external stimuli. Anim. Behav., 45: $351-358$.

Jensen P., Gustaf s s on M., A u gus ts s o n H. (1998). Teat massage after milk ingestion in domestic piglets: an example of honest begging. Anim. Behav., 55: 779-786.

L a w r e n c e A.B., T e r l o u w E.M.C. (1993). A review of behavioural factors involved in the development and continued performance of stereotypic behaviours in pigs. J. Anim. Sci., 71: 2815-2825.

Lawrence A.B., P etherick J.C., McLean K., Deans L., Chirnside J., Vaughan A., Clutton E., T e rlouw E.M. (1994). The effect of environment on behaviour, plasma cortisol and prolactin in parturient sows. Appl. Anim. Behav. Sci., 39: 313-330.

Law rence A.B., Mc Le an K.A., J arvis S., Gilbert C.L., Petherick J.C. (1997). Stress and parturition in the pig. Reprod. Domest. Anim., 32: 231-236.

Len sink B.J., Leruste H., De Bretagne T., B i zeray-Filoche D. (2009). Sow behaviour towards humans during standard management procedures and their relationship to piglet survival. Appl. Anim. Behav. Sci., 119: 151-157. 
L o u Z., H urnik J.F. (1998). Peripartum sows in three farrowing crates: posture patterns and behavioural activities. Appl. Anim. Behav. Sci., 58: 77-86.

Ma letinska J., S p in k a M. (2001). Cross-suckling and nursing synchronisation in group housed lactating sows. Appl. Anim. Behav. Sci., 75: 17-32.

Marchant J.N., B room D.M., Corning S. (2001). The influence of sow behaviour on piglet mortality due to crushing in an open farrowing system. Anim. Sci., 72: 19-28.

Meli s ova M., I $11 \mathrm{~m}$ an G., Ander sen I.L., V a s d a 1 G., H a m a n J. (2011). Can sow pre-lying communication or good piglet condition prevent piglets from getting crushed? Appl. Anim. Behav. Sci., 134: 121-129.

M e un i er - S a la ün M.C., D a n tzer R. (1990). Behaviour-environment relationships in pigs: importance for the design of housing and management systems in intensive husbandry. Pig News Inf., 11: 507-514.

Now a k R., P orter R.H., Lev y F., Orge ur P., S c ha a l B. (2000). Role of mother-young interactions in the survival of offspring in domestic mammals. Rev. Reprod., 5: 153-163.

N o w i c k i J., K l o c e k C. (2004). Relations between interest in litter/replacing activities and prolactin level in sows housed in periparturient period in three farrowing environments. Ann. Anim. Sci., Suppl. 1: 239-242.

N ow i c k i J., K l o c e k C. (2006). Preliminary observations of sows' behaviour potentially dangerous for piglets in three farrowing environments. Ann. Anim. Sci., Suppl. 2 (2): 385-390.

N ow i c ki J., K l o c e k C., K o c zan ow s k i J., T u z R. (2003). Appearance of abnormal behaviour in periparturient sows housed with and without straw bedding (in Polish). Rocz. Nauk. Zoot., Suppl., 17 (2): 767-770.

Now i c ki J., S c hwarz T. (2010). Maternal responsiveness of sows housed in two farrowing environments measured in behavioral tests. Ann. Anim. Sci., 10: 179-186.

P a j or E.A., K r a m e r L., F r a s e r D. (2000). Regulation of contact with offspring by domestic sows: temporal patterns and individual variation. Ethology, 106: 37-51.

P e t e r s e n V., R e c e n B., V e s t e r g a a r d K. (1990). Behaviour of sows and piglets during farrowing under free range conditions. Appl. Anim. Behav. Sci., 26: 169-179.

P e t e r s e n V., S i m o n s e n H.B., L a w s o n L.G. (1995). The effect of environmental stimulation on the development of behaviour in pigs. Appl. Anim. Behav. Sci., 45: 215-224.

P it ts A.D., W e ary D.M., Fras e r D., P a j or E.A., Kra mer D.L. (2002). Alternative housing for sows and litters. Part 5. Individual differences in the maternal behaviour of sows. Appl. Anim. Behav. Sci., 76: 291-306.

Ring genberg N., B ergeron R., M e unier-S a lä̈n M.C., D e villers N. (2012). Impact of social stress during gestation and environmental enrichment during lactation on the maternal behavior of sows. Appl. Anim. Behav. Sci., 136: 126-135.

Rush en J., R o bert S., F a r m e r Ch. (2001). Evidence of a limited role for prolactin in the preparturient activity of confined gilts. Appl. Anim. Behav. Sci., 72: 309-319.

S i l e rova J., S p in k a M., S arova R., S la mova K., A l ger s B. (2006). A note on differences in nursing behaviour on pig farms employing individual and group housing of lactating sows. Appl. Anim. Behav. Sci., 101: 167-176.

Spinka M., Illmann G., A lgers B., Stetkova Z. (1997). The role of nursing frequency in milk production in domestic pigs. J. Anim. Sci., 75: 1223-1228.

S t a n g e 1 G., J e n s e n P. (1991). Behaviour of semi-naturally kept sows and piglets (except suckling) during 10 days postpartum. Appl. Anim. Behav. Sci., 31: 211-227.

S tolba A., W o od-Gush E.G.M. (1989). The behaviour of pigs in a semi-natural environment. Anim. Prod., 48: 419-425.

S ve nd s e n J. (1992). Perinatal mortality in pigs. Anim. Reprod. Sci., 28: 59-67.

Th o d b e r g K., J e n s e n K.H. (2005). A test of sows' willingness to nurse. Appl. Anim. Behav. Sci., 94: 49-58.

Thodberg K., Jensen K., Herskin M.S. (1999). Influence of environmental stimuli on nest building and farrowing behaviour in domestic sows. Appl. Anim. Behav. Sci., 63: 131-144.

Thodberg K., J en se n K.H., Herskin M.S. (2002). Nest building and farrowing in sows: relation to the reaction pattern during stress, farrowing environment and experience. Appl. Anim. Behav. Sci., 77: 21-42. 
Valros A., Rundgren M., S pinka M., Saloniemi H., Algers B. (2003). Sow activity level, frequency of standing-to-lying posture changes and anti-crushing behaviour - within sow repeatability and interactions with nursing behaviour and piglet performance. Appl. Anim. Behav. Sci., 83: 29-40.

Valros A., Rungren M., Spinka M., S aloniemi H., Hulten F., Uvnas-Moberg K., To m a n e k M., Krej c i P., A lgers B. (2004). Oxytocin, prolactin and somatostatin in lactating sows: associations with mobilisation of body resources and maternal behaviour. Liv. Prod. Sci., 85: 3-13.

W e ary D.M., P a jor E.A., Thomp son B.K., Fraser D. (1996). Sow body movements that crush piglets: a comparison between two types of farrowing accommodation. Appl. Anim. Behav. Sci., 49: 149-158.

W e a r y D.M., Philli p s P.A., P a jor E.A., F r a s e r D., Tho m p s on B.K. (1998). Crushing of piglets by sows: effects of litter features, pen features and sow behaviour. Appl. Anim. Behav. Sci., 61: 103-111.

W e ch s ler B., Hegglin D. (1997). Individual differences in the behaviour of sows at the nest-site and crushing of piglets. Appl. Anim. Behav. Sci., 51: 39-49.

W i dow sk i T.M., C u r t i s S.E., D zi u k P.J., W a g n e r W.C., S h erw ood O.D. (1990). Behavioural and endocrine responses of sows to prostaglandin F2 $\alpha$ and cloprostenol. Biol. Reprod., 43: 290-297.

W i s c h n e r D., K e m pe r N., Kri e te r J. (2009). Nest building behaviour in sows and consequences for pig husbandry. Liv. Sci., 124: 1-8.

W is chner D., Ke mper N., S ta mer E., Hellbrugge B., Presuhn U., Krieter J. (2010). Pre-lying behavioural patterns in confined sows and their effects on crushing of piglets. Appl. Anim. Behav. Sci., 122: 21-27.

Accepted for printing 12 VII 2012

JACEK NOWICKI, CZESŁAW KLOCEK, TOMASZ SCHWARZ

\section{Czynniki wpływające na zachowanie matczyne i opiekuńczość loch w okresie okoloporodowym i laktacji}

\section{STRESZCZENIE}

Troskliwość macierzyńska loch wpływa na przeżywalność prosiąt determinując wyniki ekonomiczne chowu świń. Celem niniejszego opracowania jest przedstawienie interakcji pomiędzy systemem utrzymania loch $\mathrm{w}$ okresie okołoporodowym i laktacji, a zmianami hormonalnymi występującymi u macior w tym czasie oraz ich łączne oddziaływanie na zachowanie loch i poziom ich dobrostanu, które w efekcie kształtują uzyskiwane wyniki produkcyjne. Pod uwagę wzięto następujące czynniki warunkujące poziom dobrostanu loch w okresie okołoporodowym: rodzaj kojca porodowego, powierzchnię kojca, w tym wpływ systemów uniemożliwiających losze swobodę poruszania się, jak również systemy otwarte, alternatywne. Omówiono również istotność budowy gniazda dla dalszego przebiegu odchowu prosiąt, jak również strach przed obsługą, który może zniweczyć wysiłki w kierunku uzyskiwania lepszych wyników produkcyjnych w postaci większej liczby prosiąt odchowanych. 